\title{
The Elastic Bridge Plating of the Forearm Fracture: A Prospective Study
}

\author{
Ewa K. Stuermer, Stephan Sehmisch, Karl-Heinz Frosch, Thomas Rack, \\ Clemens Dumont, Mohammad Tezval, Klaus Michael Stuermer ${ }^{1}$
}

\begin{abstract}
Rigid plate osteosynthesis with compression is still the treatment of choice for forearm fractures to gain anatomic reposition, provide proper rotation and avoid a bridging callus. Due to necessary operative dissection there is a serious risk for infection and malunion. Based on good clinical results with elastic bridge plating at femur, humerus and tibia, this technique was also started to be used for forearm fractures in our clinic in 1995. In a prospective study, 86 of 124 consecutive patients at the age of $35.2 \pm 14.7$ years with 129 diaphyseal fractures of the radius or ulna (AO: 37 type $A, 36$ type $B, 13$ type C) were analyzed between January 1998 and December 2003. All fractures were stabilized by bridge plating. Radiographic union and clinical outcome were documented. Of the 129, 122 diaphyseal fractures (94.5\%) healed within $10.2 \pm 3.4$ weeks without complications (no nerve lesions, nonunion, synostosis callus). One re-osteosynthesis, one secondary lag screw, and five cancellous bone grafts were necessary before final healing. About $79.1 \%$

of the patients had a perfect clinical outcome; $17.4 \%$ had additional severe injuries of the same arm. Bridge plating without interfragmentary compression is a reliable surgical procedure even for forearm fractures with low risk of infection and nonunion.
\end{abstract}

\section{Key Words}

Forearm fracture - Elastic bridge plating - Fracture healing · Callus formation - Long bone

Eur J Trauma Emerg Surg 2009;35:147-52

DOI 10.1007/s00068-008-8002-3

\section{Introduction}

In recent years, the elastic bridge plating osteosynthesis - instead of the rigid technique with interfragmentary compression - established itself as the treatment of choice for multifragmentary fractures [1-3]. However, amongst all long bone fractures only the forearm fracture is still fixed in a rigid technique, using compression plates with or without lag screws [4-7]. The latest "Manual of Osteosynthesis" of the AO [8] justifies this procedure by the necessity of exact anatomic reposition, which is essential for the unrestricted pronation and supination. The forearm must be considered a unit, including the elbow and the radio carpal joint. Bone length, axis, rotation, and the correct interosseous space have to be exactly restored. In bridge plating, anatomical reduction is possible as well. This is achieved by minimal (less than a third of the circumference) epiperiosteal exposure of the fracture ends. This exposure allows anatomical reposition due to minimal visualization of the interdigitation of the fracture line and the contour of the diaphysis. Third fragments do not need to be prepared or reduced. In addition, the strain of the forearm is not considered to be sufficiently effective to build up callus. On the other hand, there is the risk of the formation of a bridging callus (synostosis) with disturbance of pronation and supination.

\section{Patients and Severity of Injury}

In the time period between January 1998 and December 2003, 124 consecutive patients with forearm fractures were operatively treated in our department with the elastic bridge plating. A total of 86 patients, 49 male and 37 women, at $35.2 \pm 14.7$ years of age were available for follow-up. These 86 patients had 129 diaphyseal fractures of the radius or the ulna. In 38 patients the right arm was involved (all dominant) and in 48 patients the fractures occurred in the left arm (2 dominant). In $63 \%$ of these patients the forearm fracture occurred as a monotrauma. About $14 \%$ pa-

\footnotetext{
'Department of Trauma and Reconstructive Surgery, Georg-AugustUniversity of Göttingen, Göttingen, Germany.
} 

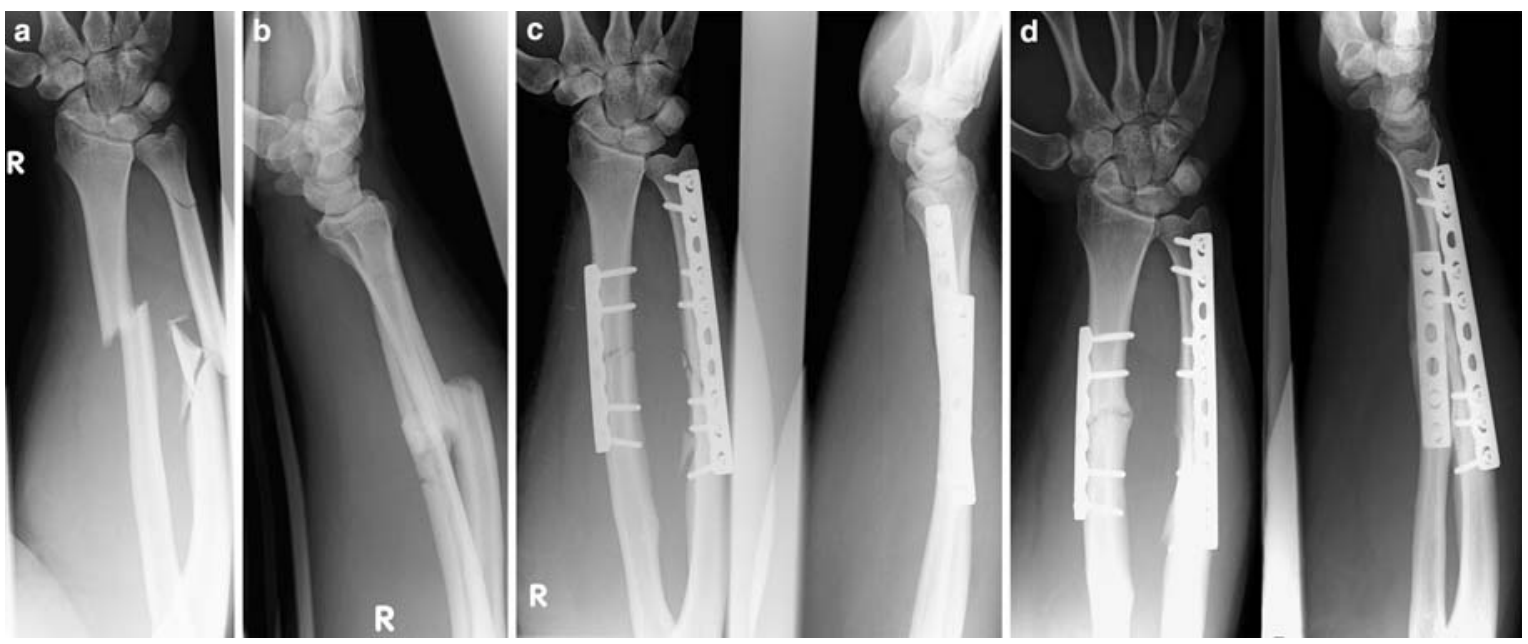

Figures 1 a to 1 d. $I^{\circ}$ open fracture of the right forearm $A O$ Type $C$. a) In the anterior-posterior view and in b) in the lateral view. c) Radiographs of the elastic bridge plating after 3 weeks with bridging at the fracture site. d) Radiograph of the forearm fractures after 5 months. Visible callus at radius and ulna, though the fracture line of the radius is still visible.

Figures 2a to 2c. a) Galeazzi lesion of the right forearm. b) Radiograph after 4 weeks with elastic bridge plating with two empty holes above the fracture. A small fragment is left in the soft tissue without repositioning (no-touch technique). Visible callus formation. c) Callus resorption after fracture healing in progress even after 5 months.
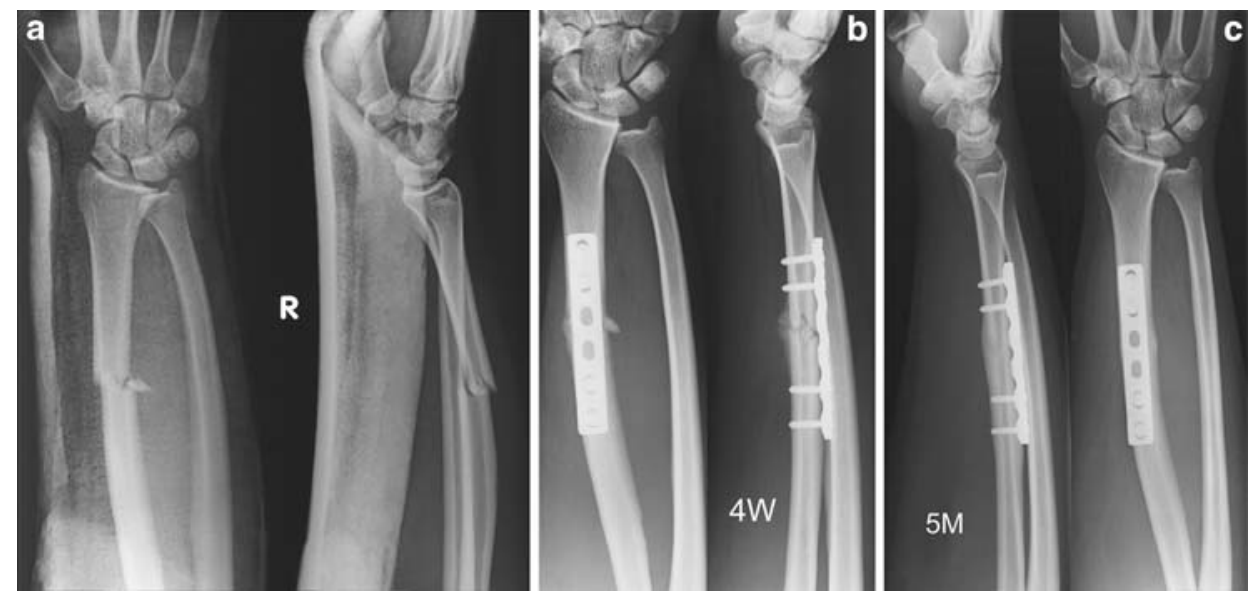

tients were multiple injured and another $23 \%$ of the patients were polytraumatized (ISS $>16$ ). Of the 86 patients, $23(27 \%)$ had open fractures $\left(\mathrm{I}^{\circ}\right.$ to $\left.\mathrm{III}^{\circ}\right)$ [9] (Figure 1). According to the classification of the AO, there were 37 fractures type A, 36 type B and 13 type $\mathrm{C}$ (Figure 1). Forty-three patients had combined diaphyseal fractures of radius and ulna. Twenty-one patients had a Galeazzi lesion (Figure 2), 20 had a Monteggia lesion and 2 had an isolated ulna fracture without joint involvement.

The other 38 of the 124 consecutive patients were rejected from this prospective study because their fracture healing was influenced by other diseases or they were not available for the follow-up evaluation: 16 polytrauma patients had severe craniocerebral injuries (4 patients died), another 3 elderly patients died from internal diseases, 2 patients were temporary visitors (not residents), 15 lived in other counties and did not want to travel for the study and of 2 patients the contact address was unknown.

Patients who had surgery within the first hours after injury kept the initial splint until surgery. The others received a cast to reduce the pain and crepitating until osteosynthesis. Analgesics (e.g., NSAR) were given as required. None of the patients were immobilized in a plaster cast during the postoperative phase. The postoperative follow-up treatment was functional, and physical stress was guided by individual pain. In-patients received physiotherapy until demission.

\section{Operating Technique}

The dorsolateral approach (Thompson approach) was used for the fracture of the radius, and the plate was positioned dorsally at the drawing side. For the ulna fracture, we used an approach parallel and just slightly 
dorsal to its palpable crest. The plate was applied on the extensor surface, the tension side of the forearm. Additional soft tissue and fragments were not damaged and exposure was epiperiosteal each time. The fractures of the radius and ulna were stabilized by the titanic AO Dynamic Compression Plate $(3.5 \mathrm{~mm}$ LCDCP, Synthes, Switzerland) or the AO titanium one-third tubular, small-fragment plate (Synthes, Switzerland). We considered it of sufficient strength to support functional loading and exercise during the bone healing. A minimum of four, but preferably six cortices in the two main fragments of the fracture was fixed with screws. At the fracture site itself, one to three plate holes were used for bridging. Anatomical reduction of the main fragments was achieved by minimal (less than a third of the circumference) epiperiosteal exposure of the fracture ends, so that the blood supply was not hampered in that area. No interfragmentary compression via lag screws or plate holes was induced. No bone grafts were used primarily with the exception of $\mathrm{IIb}^{\circ}$ and $\mathrm{III}^{\circ}$ open fractures with serious bone loss. Nine different surgeons of all levels of experience performed the operating procedures. All patients received a single dose of antibiotics [Cefazolin ${ }^{\circledR}$ (Fresenius medical care) $2 \mathrm{~g}$ i.v.] before surgery; patients with open fractures received antibiotics depending on the degree of tissue damage and the antibiogram.

\section{Evaluation}

Patients were monitored routinely during the postoperative phase at $4,8,12$ weeks and 6 months, if necessary more often and additionally at 12 months (see "Complications"). Radiographs were analyzed for changes in fracture alignment, implant loosening, and the fracture healing process. Fracture union was defined when callus formation was calcified, the bone was radiographically healed, and the patient was clinically asymptomatic. The functional result was evaluated after trauma at 6 and 12 months, respectively. The evaluation of the radiographs was performed by an independent blinded observer.

\section{Surgical Procedure}

Of the 86 patients available for follow-up, 47 were treated with immediate surgery within 6 hours, another 13 within 24 hours. The other 26 patients had surgery within the first 4 days after trauma. The AO titanium LCDC plate $(3.5 \mathrm{~mm}$, Synthes, Switzerland) was used at 107 fractures and the AO titanium one-third tubular, small-fragment plate (Synthes, Switzerland) was used in 22 cases (children, ulna distally). In seven patients with open fractures, we initially added a cancellous bone graft because of avital fragments or bone loss. In three of these seven patients, in addition, an external fixator with transfixation of the elbow joint was used temporarily because of soft tissue damage of III $^{\circ}$ open fractures.

\section{Results \\ Fracture Healing}

All 86 patients with 129 diaphyseal fractures of the forearm were analyzed. Of the 129 fractures 122 $(94.5 \%)$ healed without any disturbances within $10.2 \pm 3.4$ weeks (mean \pm SD) with visible callus formation (Figures $2 b, 2 c$ ), and without complications. (For the seven fractures with delayed healing see "Complications" below.) In 51 of the 86 patients the plates were removed within 4-19 months. This high rate $(59 \%)$ of removals was performed upon patients' requests: forearm fractures are injuries of younger patients (elderly suffer rather from metaphyseal radius and ulna fractures due to osteoporosis) who felt disturbed by the implants while exercising. Other patients complained of disturbance when the arm with the ulna plate was leaning on the table for example. After implant removal no refracture occurred. In the other 35 patients the plates were not removed [10], as they did not cause any disturbance or pain.

\section{Functional Results}

Measured by the Neutral-0 Method 68 of the 86 patients $(79.1 \%)$ had free function of the elbow, forearm and wrist and the same range of motion compared to the contralateral limb. (Range of motion: elbow flexion $120^{\circ}$ to $150^{\circ}$, extension $-10^{\circ}$ to $0^{\circ}$; supination $70^{\circ}$ to $90^{\circ}$, pronation $70^{\circ}$ to $90^{\circ}$; wrist flexion $60^{\circ}$ to $90^{\circ}$, extension $70^{\circ}$ to $100^{\circ}$ ). Among them were 34 patients with combined diaphyseal fractures of the radius and the ulna. Of the other 18 patients, 15 had additional severe injuries of the arm, which influenced the functional outcome decisively: six had lesions of the nerves and/or the vessels, four had multifragmentary fractures of the radial head, another four primarily had a dislocation of the elbow and one had a combination of forearm, olecranon and humerus fractures of the injured arm. (Range of motion: elbow flexion $50^{\circ}$ to $120^{\circ}$, extension $0^{\circ}$ to $40^{\circ}$; supination $30^{\circ}$ to $90^{\circ}$, pronation $20^{\circ}$ to $80^{\circ}$; wrist flexion $30^{\circ}$ to $70^{\circ}$, extension $20^{\circ}$ to $80^{\circ}$ ). Only three patients with a "simple" Galeazzi lesion suffered from a rotational deficit of the forearm between $20^{\circ}$ and $50^{\circ}$ of supination; flexion and extension of the elbow and wrist were free. 

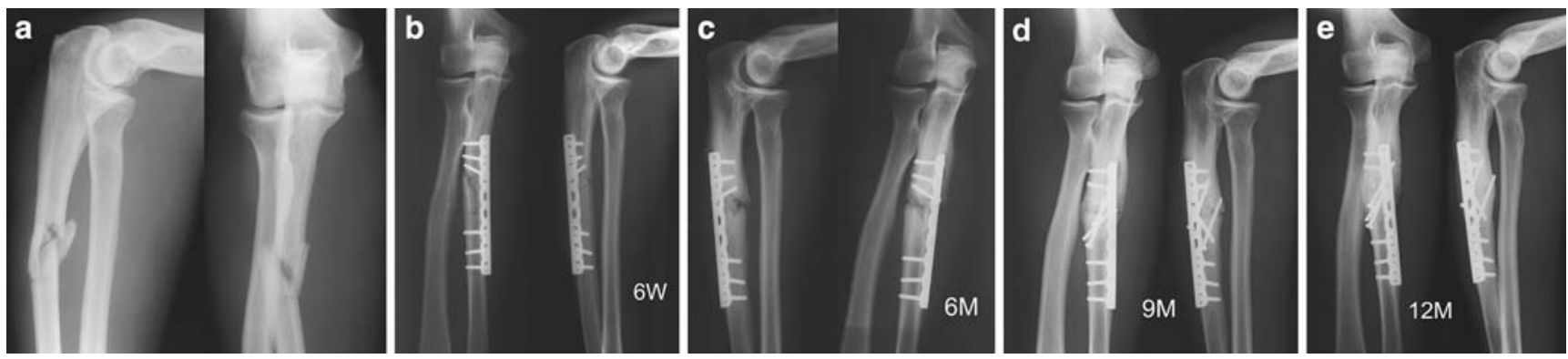

Figures за to зe. a) Isolated multifragmentary ulna fracture of the right forearm after a direct trauma. b) Plate osteosynthesis with a bridging of two empty holes. The third proximal screw touched the fracture line so that elasticity was not achieved in the fracture region. c) Lack of callus formation due to the lack of elasticity, which normally triggers the fracture healing. Due to instability of the fracture more callus formation is visible at the proximal plate than at the fracture site to "stabilize" the internal fixation. d) Fracture after second operation (9 months) with callus fixation with two lag screws. No cancellous bone graft was used. e) Delayed fracture healing with hypertrophic callus formation.

\section{Complications}

There was no additional (intraoperative) nerve lesion, no infection, and no bridging (synstostosis) callus in all 86 patients. In 7 of 129 fractures $(0.5 \%)$, additional operations were necessary: one reosteosynthesis was done after plate loosening at the ulna after 7 weeks due to patient non-compliance. Five secondary cancellous bone graftings were necessary in cases of delayed fracture healing (5-8 months after trauma). In only one of these patients we had to change the internal fixation into a longer plate. In one other patient, we fixed the vital callus with two lag screws to obtain fracture healing (Figure 3). All seven fractures healed within 12 weeks of the described surgical procedure.

\section{Discussion}

The operative treatment of diaphyseal forearm fractures requires a well-considered and adequate therapy corresponding to the patient age and fracture type. Today it is not only the aim, but also the requirement, to achieve a treatment result without any loss of function or range of motion, and without disability of the forearm, elbow, and wrist movements. The rigid plate osteosynthesis with absolute stability, which we had also performed for several years, had a relatively high incidence of nonunion and refractures, especially after hardware removal [11-16]. We postulate that this is a result of devascularization of the bone and the surrounding soft tissue during direct open reduction necessary in rigid anatomic fixation. The latest AO-Manual of Fracture Management - Internal Fixators [8] describes the surgical technique of rigid anatomic fixation as follows: "exact anatomic reposition implies that the fracture area is exposed surgically or is wide open. Instruments are directly applied to each fragment, usually very near the fracture site. To allow access, it may be necessary to strip muscles from the fragments or extraperiosteal exposure is required. A temporary fixation device such as a clamp or a K-wire is often applied, and fixation then follows, usually with lag screws, which demand further tissue preparation or deperiostation." In addition, lag screws may compromise the vascularization indirectly due to the propagation and enlargement of microfractures, which were the main causes of devascularization of the fracture ends [17-19]. The basic conception of the elastic (titanium) osteosynthesis is the "no touch" technique of the fracture region; vascularization should be less disturbed than in the rigid technique.

For diaphyseal bone, compression between fragments is neither suitable nor necessary. This is in contrast to Lindvall [20], who combined indirect reduction with interfragmentary compression. Under physical stress, micro movements between the main fragments are allowed and desired. In comparison, the elastic osteosynthesis of long bone diaphysis with the intramedullary nail is not combined with lag screws or other type of compression, and the results of fracture healing are good. The question arises why (elastic) plate osteosynthesis of radial or ulnar diaphysis should inevitably require a lag screw or compression if the formation of a callus is desired? In contrast to what is often postulated, the strain of daily use of the injured arm is enough stimulation for triggering callus formation.

Histomorphologic investigations date the first woven-bone bridges between the fragments 2-4 weeks after trauma [3, 21]. If done correctly, with preservation of soft tissue and bone, delayed bone healing, nonunion, or bone infections rarely occur when elastic bridge plate osteosynthesis is applied. The risks of this technique arise from an "unbiological" and exaggerated reduction, a too short flexible stretch, insufficient anchorage of the screw, and unnoticed interposition of soft tissue [17]. The plate osteosynthesis of shaft frac- 
tures should be performed right from the beginning either in the rigid technique with absolute stability or in the bridging technique with elasticity, but never in a combination of both.

In this prospective study, 6 of the 129 fractures $(0.5 \%)$ showed delayed fracture healing. In the analysis of these six fractures, we came to the conclusion that the reason for the failure of the elastic bridge plating osteosynthesis was incorrect, neither "elastic" nor "biologic", operating technique: In the six patients, the distance between the fracture and the next plate screws was too short $(<15 \mathrm{~mm})$. This resulted in a lack of micro motion between the fragments, with insufficient callus formation. Additionally, in two of these patients the fracture was temporarily fixed with lag screws during surgery. They were removed at the end of the operation, but had obviously disturbed the vascularization at the fracture site.

Nevertheless, we postulate that the complications of the biologic elastic plate osteosynthesis are rare and easier to manage than in rigid fixation and failed primary bone healing because the vascularization of the fracture region is preserved. Delayed fracture healing occurs always with this technique with hypertrophic bone formation. Therefore, after re-operation all these fractures healed quickly. The hypertrophic callus formation requires additional stability at this stage of the healing process. This can be achieved by stable, rigid fixation, e.g., with lag screws. At this point of fracture healing, the callus formation is already sufficiently triggered by micro movement. The remaining problem is the final bone bridging, which can be assisted by stability. Cancellous bone grafting is only necessary in bony defects.

For all cases no infection, no bridging callus (synostosis), and no nerval lesion was observed. A reason for this may be the avoidance of additional trauma to the soft tissue and to the fracture region during operation. In contrast, the operative stabilization of radius fractures with rigid plates had a high risk of damage to the sensory or dorsal interosseous branch of the radial nerve [22,23]. The reasons for the higher risk may be the necessity of a wider approach and the reposition manoeuvre, which requires more manipulation of the bone and a more pronounced use of instruments. With regard to this point, the elastic bridge plating seems to be additionally advantageous, though not an easy surgery.

The complications, which occurred by applying the rigid plate osteosynthesis, led to the development of intramedullary forearm nails. In the beginning, the rate of pseudoarthrosis with intramedullary nails was high $(20 \%)$ and independent of the type of intramedullary nails used [24]. The cause was rotational instability
[24-26]. Therefore, the primary concept of intramedullary fixation of forearm fractures of 1913 [26] developed further during recent years: U-shaped nails like the Kuentscher nail, nails of triangulated shape [27], of square shape [18], or nails with distal and proximal interlocking [18], were invented. Regarding the operation technique, the ulna, being a straight bone, is more amenable to intramedullary nailing than the radius. However, the intramedullary nail osteosynthesis of the forearm did not replace the plate osteosynthesis, with the exception of operative pediatric traumatology (commonly used in combination with a splint) [28-31].

Due to the "no touch" technique and due to no direct fixation at the fracture region, the biologic elastic bridge plating induces periosteal callus formation [3]. For years, one of the most important goals in the treatment of forearm fractures was to avoid callus formation, because of the risk of a bridging callus (synostosis) with abolition of forearm rotation. Therefore, the rigid plate osteosynthesis and primary bone healing seemed to be the best operating technique at this location [32]. However, in the presented prospective study none of the patients developed a posttraumatic synostosis. They had callus formation of a different extent, but no synostosis occurred. Furthermore, examination of the radiographs of all involved 86 patients showed that no patient was ever at risk of developing a posttraumatic synostosis. To this end, we postulate that the formation of a bridging callus depends on the extension of soft tissue damage due to the traumatic lesion, on the operating technique, or on accompanying head or spinal cord injuries [33-35]. The elastic bridge plating allows micro movements but no exaggerated motion, which causes excessive callus formation.

A majority $(79.1 \%)$ of the study patients had unrestricted pronation, supination and free motion of wrist and elbow joints; $17.4 \%$ of the others had additional severe injuries of the arm, which influenced the functional outcome decisively. As the forearm must be considered as a unit - including the elbow joint and the radio carpal joint - bone length, axis, rotation and the correct interosseous space had to be exactly restored. Therefore, the surgical technique of bridge plating is demanding and requires constant radiographic control intraoperatively.

\section{Conclusion}

The elastic biological plate osteosynthesis without interfragmentary compression and without lag screws is a reliable procedure of internal fixation even for the 
diaphyseal forearm fracture. It rarely shows complications, especially with regard to the risk of infections and non-union, though it does require the trauma surgeon to protect the soft tissue and to preserve the periosteal vascularization. The surgical challenge is the indirect repositioning into an anatomic position of the radius and ulna. The principles of the elastic fracture fixation have to be complied biomechanically.

\section{References}

1. Heitemeyer U, Kemper F, Hierholzer G, Haines J. Severely comminuted femoral shaft fractures: treatment by bridgingplate osteosynthesis. Arch Orthop Trauma Surg 1987;106:327-330.

2. Kleining, Rhax PM. Internal bridging osteosynthesis without reposition of the fragments as an alternative method to internal fixation with anatomical reposition of multifragmentary fractures. Unfallheilkunde 1981;153:213-23.

3. Schmidtmann U, Knopp W, Wolff C, Stürmer KM. Results of the elastic bridge plating of the simple femoral fractures in polytrauma patients. An alternative to common surgical techniques. Unfallchirurg 1997;100:949-56.

4. Eijer H, Hauke C, Arens S, Printzen G, Schlegel U, Perren SM. PCFix and local infection resistance - influence of implant design on postoperative infection developement, clinical and experimental results. Injury 2001;32:B38-43.

5. Claudi B, Schläpfer F, Cordey J, Perren SM, Allgoewer M. Die schräge Plattenzugschraube - in-vitro-Messung der Stabilität an queren Osteotomien des Tibiaschaftes. Helv Chir Acta 1990;46:177-82.

6. Hertel R, Pisan M, Lambert S, Ballmer FT. Plate osteosynthesis of diaphyseal fractures of the radius and ulna. Injury 1996;27:545-8.

7. Mackay D, Wood L, Rangan A. The treatment of isolated ulna fractures in adults: a systematic review. Injury 2000;31:565-70.

8. Mueller ME, Allgoewer M, Schneider R, Willenegger $\mathrm{H}$. Manual of internal fixation. Techniques recommended by the AO-ASIF group, 3rd edn. Springer, Berlin, 2003.

9. Oestern HJ, Tscherne $\mathrm{H}$. Pathophysiology and classification of soft tissue damage in fractures. Orthopaede 1983;12:2-8.

10. Labosky DA, Cermak MB, Waggy CA. Forearm fracture plates: to remove or not to remove. J Hand Surg [Am] 1990;15:294-301.

11. Chapman MW, Gordon JE, Zissimos AG. Compression plate fixation of acute fractures of the diaphysis of the radius and ulna. J Bone J Surg [Am] 1989;71:159-69.

12. Deluca PA, Lindsey RW, Rowe PA. Refracture of bones of the forearm after removal of compression plates. J Bone J Surg [Am] 1988;70:1372-76.

13. Gunst MA, Suter C, Rahn BA. Die Knochendurchblutung nach Plattenosteosynthese. Eine Untersuchung an der intakten Kaninchentibia mit Disulfinblau-Vitalfärbung. Helv Chir Acta 1979;46:171-5.

14. Hughston JC. Fractures of the distal radius shaft: mistakes and management. J Bone J Surg [Am] 1957;39:249-64.

15. Schemitsch EH, Richards RR. The effect of malunion on functional outcome after plate fixation of fractures of both bones of the forearm in adults. J Bone J Surg [Am] 1992;68:1068-78.

16. Stern PJ, Drury WJ. Complication of plate fixation of forearm fractures. Clin Orthop Relat Res 1983;175:25-9.
17. Stuermer KM, Schuchard W. New aspects of intramedullary nailing and reaming of the shaft in long bones in animal experiments. Part III: Fracture healing, vascularization and bone remodelling. Unfallheilkunde 1980;83:433-45.

18. Street DN. Intramedullary forearm nailing. Clin Orthop Relat Res 1986;212:219-30.

19. Stuermer KM. Pathophysiolgy of the delayed fracture healing. Orthopäde 1996;25:86-393.

20. Lindvall EM, Sagi HC. Selective screw placement in forearm compression plating: results of 75 consecutive fractures stabilized with 4 cortices of screw fixation on either side of the fracture. J Orthop Trauma 2006;20:157-63.

21. Stuermer KM. Elastic plate osteosynthesis, biomechanics, indications and technique in comparison with rigid osteosynthesis. Unfallchirurg 1996;99:816-29.

22. Hadden WA, Reschauer R, Seggl W. Results of AO plate fixation of forearm shaft fractures in adults. Injury 1983;15:44-52.

23. Moore TM, Klein JP, Patzakis MJ, Harvey JP Jr. Results of compression-plating of closed Galeazzi fractures. J Bone J Surg [Am] 1985;67:1015-21.

24. Smith H, Sage FP. Medullary fixation of forearmfractures. J Bone J Surg [Am] 1957;39:91-8.

25. Aho AJ, Nieminen SJ, Salo U, Luoma R. Antebrachium fractures: rush pin fixation today in the light of late results. J Trauma 1984;24:604-10.

26. Schoene G. Treatment of forearm fractures with bolt. Munch Med Wochenschr 1913;60:23-7.

27. Sage FP. Medullary fixation of fractures of the forearm. J Bone J Surg [Am] 1959;41:1489-93.

28. Jubel A, Andermahr J, Isenberg J, Issavand A, Prokop A, Rehm KE. Outcomes and complications of elastic stable intramedullary nailing for forearm fractures in children. J Pediatr Orthop 2005;14:375-80.

29. Calder PR, Achan P, Barry M. Diaphyseal forearm fractures in children treated with intramedullary fixation: outcome of K-wire versus elastic stable intramedullary nail. Injury 2003;34:278-82.

30. Lascombes P, Prevot J, Ligier JN, Metaizeau JP, Poncelet T. Elastic stable intramedullary nailing in forearm shaft fractures in children: 85 cases. J Pediatr Orthop 1990;10:167-71.

31. Van der Reis WL, Otsuka NY, Moroz P, Mah J. Intramedullary nailing versus plate fixation for unstable forearm fractures in children. J Pediatr Orthop 1998;18:9-13.

32. Mueller ME, Allgoewer $M$, Willenegger $\mathrm{H}$. Manual of internal fixation. Springer, Berlin, 1969.

33. Garland DE, Jones RC, Kunkle RW. Upper extremity fractures in the acute spinal cord injured patient. Clin Orthop Relat Res 1988;233:110-5.

34. Gerber C, Mast JW, Ganz R. Biological internal fixation of fractures. Arch Orthop Trauma Surg 1990;109:295-303.

35. Hranilovic B, Nikolic R, Pericic D. Injuries of the radial nerve in fractures of the forearm. Acta Chir lugosl 1977;24:281-4.

\section{Address for Correspondence}

Ewa K. Stuermer, MD

Department of Trauma and Reconstructive Surgery

Georg-August-University of Göettingen

Robert-Koch-Straße 40

37099 Göttingen

Germany

Phone (+49/551) 392462, Fax 398991

e-mail: e.k.stuermer@med.uni-goettingen.de 